\title{
A onça no condomínio: o papel dos corredores ecológicos urbanos
}

\author{
Homero Marconi Penteado \\ Universidade Federal do Espírito Santo, Departamento de Arquitetura e Urbanismo, Vitória, ES, Brasil. \\ E-mail: homero.penteado@ufes.br
}

Submetido em 20 de julho de 2019 . Aceito em 18 de dezembro de 2019.

\begin{abstract}
Resumo. Espaços livres podem proporcionar habitat para fauna nativa em áreas urbanas, mas espécies de maior porte são raramente avistadas. Uma onça parda (Puma concolor) foi capturada em vídeo em Piracicaba, SP, o que despertou o interesse em investigar quais padrões paisagísticos (formas, dimensões, relações espaciais entre a matriz urbana, corredores $e$ fragmentos de habitats, vegetação etc.) possibilitaram os deslocamentos da zona rural para uma cidade de aproximadamente 400 mil habitantes. Utilizaram-se imagens de satélite, fotografias e mapas interpretativos. A onça foi avistada em dois pontos próximos, dos quais foram traçadas rotas para identificar prováveis percursos e refúgios. Os possíveis corredores ecológicos identificados incluem espaços sob linhas de transmissão de energia elétrica cercados por muros de condomínios, matas ciliares ao longo de córregos e do rio Piracicaba ou mesmo avenidas arborizadas que permeiam a cidade, conectam a matriz urbana com áreas rurais e dão acesso a fontes de alimentos (capivaras, animais domésticos). A presença do felino na área urbana pode decorrer de condições que o expulsaram de seus habitats, mas também de elementos atrativos e de padrões paisagísticos que criaram corredores ecológicos e propiciaram seus deslocamentos pela cidade.
\end{abstract}

Palavras-chave. corredor ecológico, espaço livre, biodiversidade, morfologia urbana, ecologia da paisagem.

\section{Introdução}

Uma paisagem, para a ecologia da paisagem, pode variar de hectares a quilômetros quadrados, compreendendo áreas heterogêneas onde ecossistemas se repetem e interagem de forma similar, compostas por comunidades (fragmentos e corredores) rodeadas por uma matriz com uma estrutura ou composição distinta (Forman, 1995). Estrutura, função e mudança são os principais focos do estudo da ecologia da paisagem (Forman e Godron, 1986; Baschak e Brown, 1995; Hobbs 1997; Moss, 2000). Conforme resume Hobbs, "a estrutura da paisagem pode ser considerada a relação espacial entre elementos da paisagem ou fragmentos; função - ou processo - é a interação entre os elementos espaciais e mudança é a alteração da estrutura e da função ao longo do tempo" (Hobbs, 1997, p.3). Mudança é representada por qualquer alteração na estrutura e/ou função (Forman e Godron, 1986; Hobbs, 1997) e pode decorrer de processos naturais ou atividades humanas, como tempestades, inundações, fogo, urbanização, mudanças de zoneamento, sucessão ecológica, incêndios florestais, mudanças climáticas, entre outros.

Quando paisagens naturais se convertem em arranjos urbanos, processos ecológicos movimentos, fluxos de espécies e conectividade - são afetados (Alberti, 2005; Forman, 2008; Beardsley et al, 2009). A urbanização é uma importante causa de perda e fragmentação de habitats, o que modifica diretamente a habilidade de espécies da fauna nativa dispersarem pela paisagem (Schumaker, 1996; Opdam et al., 2006). Entretanto, espaços livres urbanos podem proporcionar habitat e abrigo para certas 
espécies, ao mesmo tempo que desempenham funções socioculturais, acomodando, especialmente, atividades de recreação e lazer. Indivíduos de espécies de maior porte, no entanto, são raramente avistados em áreas urbanas. A estrutura da paisagem pode influenciar o comportamento de organismos. Animais podem se aventurar para além de seus habitats naturais se seus recursos reduzirem, expondo-os a riscos. Há uma forte relação entre as características e a distribuição dos espaços livres nas cidades e seus efeitos nos processos ecológicos (Forman e Godron, 1986; Arendt et al., 1994; Hough, 2004; Alberti, 2005).

Em duas ocasiões distintas, um espécime de onça parda (Puma concolor) foi registrado em vídeo em dois locais dentro da área urbana de Piracicaba, SP. Primeiro, uma câmara da portaria de um condomínio de casas registrou a presença de um indivíduo (Rocha, 2017). Meses depois, foi feito um segundo registro da onça percorrendo uma avenida da cidade, a menos de $2 \mathrm{~km}$ do primeiro (Azanha, 2019). Em função da ocorrência fortuita dessa espécie na cidade, tratar-se-á aqui como um único indivíduo, apesar de não ser possível confirmar tal fato. Despertou-se o interesse em investigar quais padrões de paisagem possibilitaram os deslocamentos desse indivíduo da zona rural para áreas urbanas de uma cidade de porte médio.

Em matrizes urbanas, corredores são, em muitos casos, os únicos remanescentes de natureza; ocorrem geralmente sob a forma de parques lineares ou faixas que acompanham cursos d'água e protegem nascentes. Remanescentes de ecossistemas originais de maiores dimensões são mais comuns em fragmentos situados em áreas rurais. Forman (1995) aponta as várias funções dos corredores, dentre elas, destacam-se seus importantes papéis de proteção da biodiversidade e de sustentação de rotas de dispersão. Corredores podem ser naturais, serpenteantes, como cursos d'água, ou artificiais, retos, como estradas, canais, ou áreas protegidas debaixo de linhas de transmissão de energia elétrica. Apresentam riqueza de espécies generalistas, multihabitat, de borda e invasoras. Podem também funcionar como sumidouros em função de atropelamentos e outros conflitos (Forman, 1995). Animais usam corredores como canais para movimentos diários, dispersão, acasalamento e migração.

Discussões sobre corredores em ambientes urbanos estão cada vez mais presentes entre urbanistas e arquitetos paisagistas. Vários termos vêm sendo comumente utilizados para caracterizar corredores, como corredor ecológico, corredor verde urbano ou greenway. Este último tem sido importante para abordar a discussão da conservação da biodiversidade em áreas urbanas (Ndubisi et al., 1995; Ahern, 2002; Bryant, 2006). Greenway tem sido traduzida como via verde (Penteado e Alvarez 2007), mas também como sinônimo de corredores verdes urbanos, ou mesmo de infraestrutura verde (Pellegrino et al., 2006), talvez sendo mais adequada a tradução por parque linear (Giordano e Riedel, 2008). Neste estudo, entendem-se corredores como estruturas capazes de conduzir movimentos ou servirem de habitat que sustentem ou suportem biodiversidade no espaço urbano enquanto componentes de sistemas de espaços livres. Tendo em vista essa importante função na história de vida de determinadas espécies, mas também para as funções urbanas, usa-se aqui a denominação corredor ecológico, podendo ser referido simplesmente como corredor. Corredor ou corredor ecológico são usados, então, neste texto, como aqueles espaços pertencentes ao sistema de espaços livres urbanos que apresentam condições para possibilitar a dispersão da fauna nativa. Entendem-se por espaços livres as áreas não edificadas, podendo ser públicas ou privadas, compreender áreas agrícolas ou florestais, áreas de conservação e fragmentos de ecossistemas nativos, assim como áreas não edificadas nas cidades como parques e praças, entre outros (Penteado, 2013). Sistemas de fragmentos de ecossistemas associados a corredores interconectados e entrelaçados com uma paisagem, quando vinculados com fontes internas e externas à matriz, conformam redes de habitats (Cook, 1991).

Assim, o objetivo deste trabalho é analisar a estrutura da paisagem e dos espaços livres (forma, dimensões, relações espaciais, estrutura, vegetação etc.) para compreender como padrões paisagísticos possibilitaram os deslocamentos da onça dentro do tecido urbano. Tais aprendizados podem ser incorporados em planos que incluam preocupações com biodiversidade. 
Considera-se, também, que alguns fatores podem ter repelido o felino de seus habitats naturais e o atraído para a zona urbana, como a perda de habitats e de fontes de alimentos, expansão de atividades humanas e urbanização, ou mesmo a abundância de alimentos no perímetro urbano.

\section{Métodos}

\section{Área de estudo}

A área de estudo compreende um recorte do município de Piracicaba que abrange parte da área interna ao perímetro urbano e regiões adjacentes a esse limite, situadas já na zona rural (Figura 1). Esse recorte territorial, com aproximadamente $50 \mathrm{~km}^{2}$, foi proposto de maneira a possibilitar inferir sobre as relações mais próximas com os locais onde a onça foi avistada.

O município de Piracicaba possui $1.378 \mathrm{~km}^{2}$ e cerca de 400 mil habitantes. O perímetro urbano é cercado por áreas agrícolas com predominância do cultivo de cana-de-açúcar. $\mathrm{O}$ rio Piracicaba percorre a área no sentido leste - oeste. No perímetro urbano, suas margens vem sendo objeto de inúmeros projetos que incluem a construção de calçadões e áreas de lazer, bem como projetos de recuperação da cobertura vegetal ao longo do rio, em fragmentos do entorno próximo e de matas ciliares de tributários. Em decorrência desses projetos, suas margens apresentam, em vários setores, grande cobertura vegetal composta por espécies nativas e exóticas (Figura 2 abaixo e Figura 5, mais adiante).

Utilizaram-se imagens de satélite do Google Earth como base para identificar os padrões paisagísticos e as relações espaciais entre os elementos estruturais da paisagem corredores e fragmentos de habitats. Os dados referentes à história de vida da espécie abordada, descritos abaixo, nortearam a identificação de tais padrões. Visitas foram documentadas com fotografias e mapas interpretativos. O objetivo desta etapa foi criar uma representação da área de estudo que permitisse uma fácil visualização da composição da paisagem e perceção dos arranjos de possíveis corredores e fragmentos.

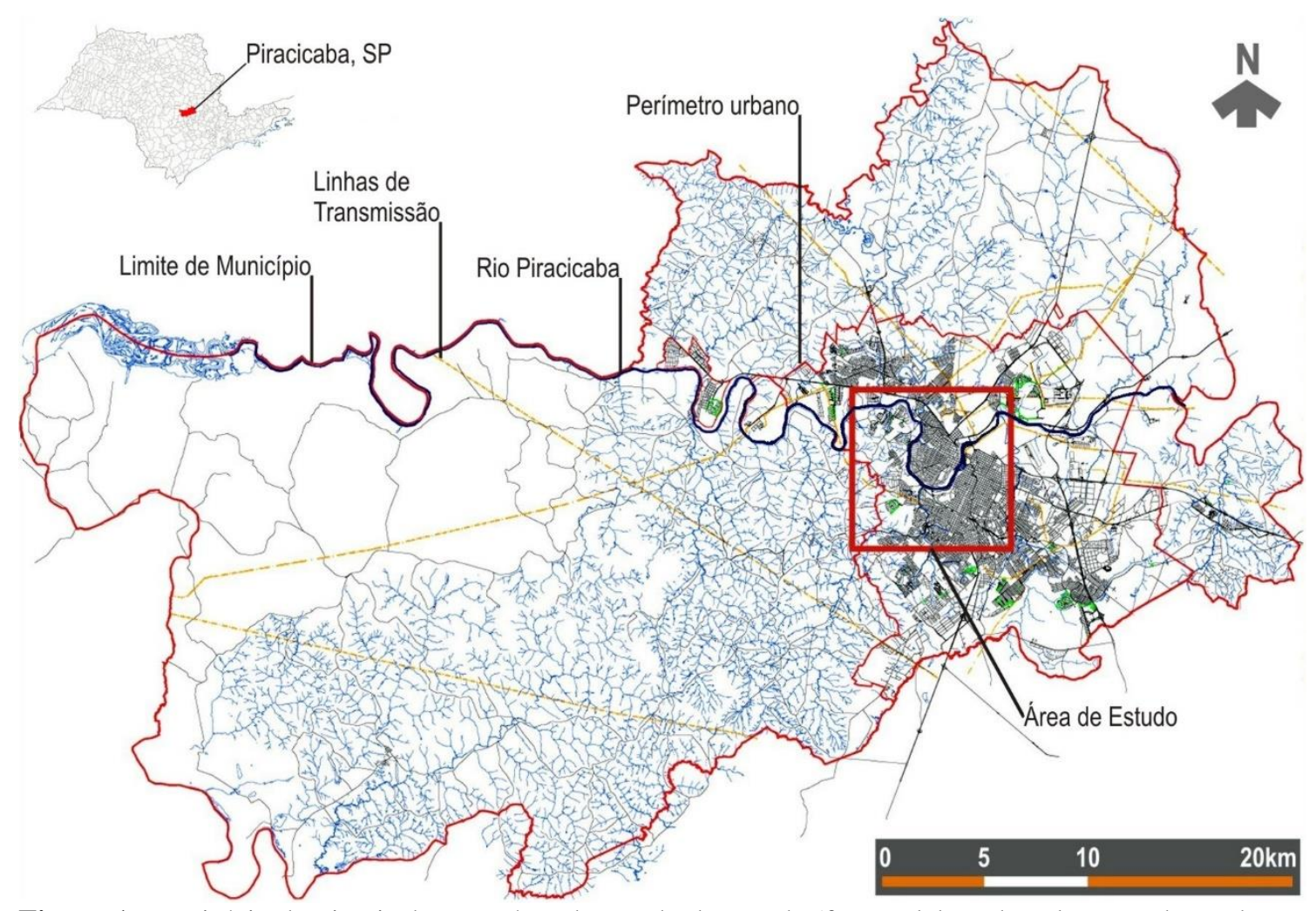

Figura 1. Município de Piracicaba com área de estudo destacada (fonte: elaborada pelo autor, baseado em mapa obtido na página do Instituto de Pesquisa e Planejamento de Piracicaba Ipplap, 2017). 

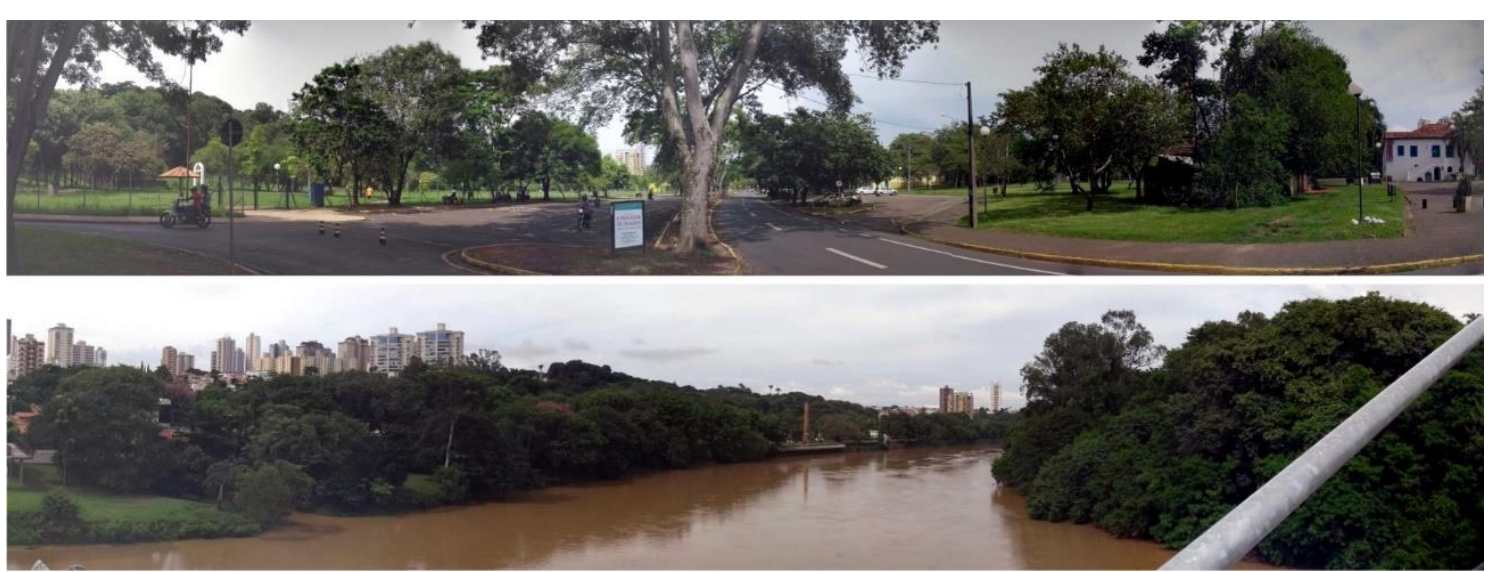

Figura 2. Ao alto, Avenida Alidor Pecorari, que atravessa o Parque da Rua do Porto, um dos locais onde a onça foi avistada. Abaixo, panorama exibe as das duas margens do rio Piracicaba, sentido jusante, tendo à margem esquerda o Parque da Rua do Porto (fonte: acervo do autor).

\section{Puma concolor}

A onça parda (Puma concolor) está presente em todo o continente americano; há múltiplas subespécies que ocorrem em vários tipos de habitat e zonas climáticas, desde desertos até florestas, em pastagens e cultivos agrícolas, de ambientes tropicais até subárticos, em altitudes que variam de 0 a $5.800 \mathrm{~m}$ (Dotta e Verdade, 2011; Azevedo et al, 2013). Na área de estudo, no sudeste brasileiro, ocorre a subespécie Puma concolor capricornensis (Azevedo et al 2018). É amplamente distribuída em áreas de cerrado e de Mata Atlântica, podendo ocupar plantações de cana-de-açúcar e habitats conectados com níveis reduzidos de cobertura vegetal; além disso, áreas de reflorestamento com níveis intermediários de distúrbios também parecem ser viáveis para a espécie (Azevedo et al., 2013). Entretanto, mesmo a espécie sendo capaz de lidar com algumas variações ambientais, habitats fragmentados ou degradados não suportam populações viáveis de felinos de grande porte (Azevedo et al., 2018). A extensão de seu território varia, dependendo da região. Há, por exemplo, registros de territórios que oscilam de 32 a $155 \mathrm{~km}^{2}$ no Pantanal, ou de 2,54 a $61,19 \mathrm{~km}^{2}$ no Parque Nacional das Emas (Azevedo et al., 2018). Em um estudo realizado na região, Penteado (2012) estimou a área de vida de um adulto macho em aproximadamente 114 $\mathrm{km} 2$, com deslocamentos diários entre $10 \mathrm{~m} \mathrm{e}$ $10 \mathrm{~km}$ e uma variação mensal entre 50 e 101 $\mathrm{km}$. A onça parda dispersa por muitos quilômetros em busca de novos territórios: na América do Norte, dependendo da disponibilidade de recursos, foram reportadas distâncias que variam de dezenas a centenas de quilômetros (Logan e Sweanor, 2010). Nos hábitos alimentares é oportunista e possui uma dieta variada composta de cervídeos, répteis, aves, peixes, insetos (Iriarte et al, 1990), capivaras, emas, cavalos, bois, pacas, cotias (Novack et al, 2005), bugios, macacos aranhas (Ferrari, 2009), quatis e mãos peladas (Scognamillo et al, 2003; Novack et al, 2005). As principais ameaças à espécie decorrem de conflitos por ataques a gado, a animais domésticos e a humanos, de atropelamentos, da caça, bem como dos processos de urbanização, de supressão, fragmentação e degradação do habitat devido, dentre outros fatores, à expansão agropecuária e queimadas (principalmente em canaviais), diminuição iminente dos remanescentes florestais, expansão da malha viária e ferroviária, e provavelmente à implantação de grandes complexos hidrelétricos (Azevedo et al, 2013, 2018). É considerada ameaçada em alguns estados brasileiros, sendo classificada como Vulnerável (VU) no estado de São Paulo (Azevedo et al, 2018).

\section{Resultados}

A partir de observações sobre a imagem aérea do recorte selecionado e de visitas exploratórias, mapearam-se os possíveis corredores percorridos pela onça. Buscou-se identificar elementos que atendam aos requisitos da espécie, que é capaz de se movimentar em áreas com coberturas vegetais variáveis e diversos graus de antropização. Partiu-se do mapeamento dos pontos onde o indivíduo foi avistado e dos possíveis corredores, considerando-se as 
distâncias diárias que essa espécie percorre e sua capacidade de dispersão.

A paisagem estudada apresenta múltiplos possíveis tipos de corredor. Estradas, linhas de transmissão de energia elétrica, cursos d'água, cercas vivas, avenidas, arborizadas ou não, permeiam a área. Destacam-se dois tipos de corredor que têm conexão direta com as áreas onde a onça foi avistada (Figura 3): o rio Piracicaba e a área debaixo da linha de transmissão de energia elétrica.

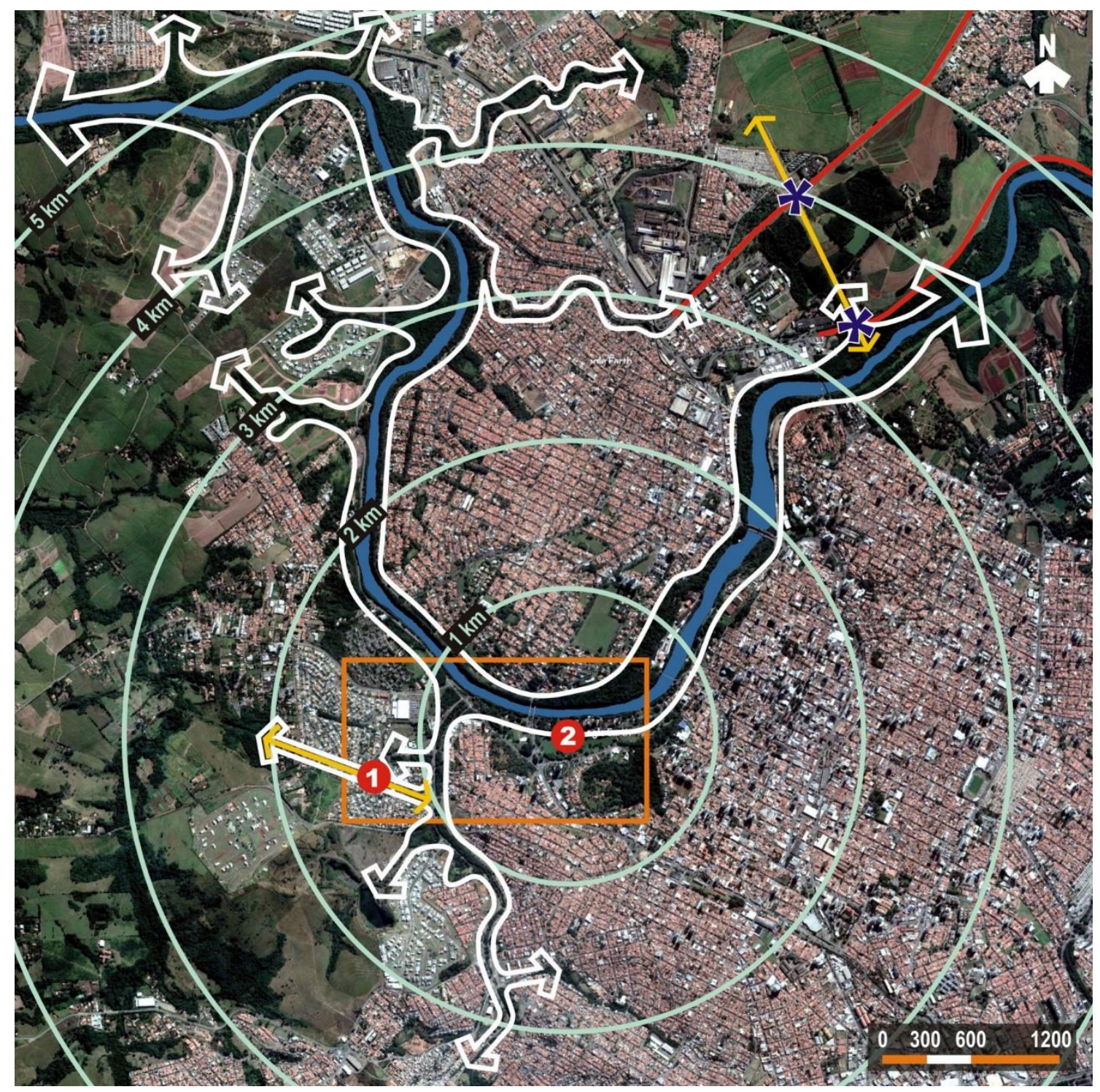

Figura 3. Possíveis corredores na área de estudo: em azul, o rio Piracicaba permeia a área urbana; setas brancas indicam possíveis percursos, incluindo áreas servidas por cursos d'água com vários níveis de cobertura vegetal; setas amarelas indicam possíveis corredores sob linhas de transmissão de energia elétrica; linhas vermelhas são rodovias estaduais; os pontos 1 e 2 correspondem aos locais onde a onça foi avistada, sendo 1) portaria de condomínio e 2) Av. Alidor Pecorari, ao longo do Parque da Rua do Porto; asteriscos em roxo apontam locais de possíveis conflitos (atropelamentos); circunferências indicam distâncias $(1 \mathrm{~km})$ a partir do ponto 2; área em laranja ampliada na Figura 4 (fonte: elaborada pelo autor sobre mosaico de imagens de satélite obtidas do Google Earth, datadas de 01 fev. 2019). Escala com medidas em metros.

O corredor fluvial é conformado pela calha e pelas margens do rio Piracicaba. Suas margens apresentam áreas urbanizadas, com alguns remanescentes de mata ciliar, áreas reflorestadas ou revegetadas, calçadões, muros de arrimo e gabiões.
Vários tributários, também com diferentes níveis de cobertura vegetal, ligam-se ao corredor do Piracicaba, ampliando, assim, as possibilidades de percurso da onça. $\mathrm{O}$ córrego Pólvora (Figura 4) situa-se entre o rio Piracicaba e o local onde a onça foi primeiramente avistada (ponto 1 nas Figuras 
3 e 4). Fragmentos vegetados também são percebidos na área, que compreende matrizes urbana e rural: chácaras, reservas legais em sítios e fazendas e plantações de cana-deaçúcar e de eucalipto. Tais fragmentos podem servir de abrigo diurno para a onça parda.

Quanto ao segundo tipo de corredor que se destaca na área estudada, verifica-se que uma linha de transmissão de energia elétrica, com cerca de $30 \mathrm{~m}$ de largura, se estende a oeste e faz a conexão entre as matrizes rural e urbana. Entrecorta um fragmento de mata, passa entre condomínios residenciais de casas (ponto 1 na Figura 3) e liga-se a leste com o corredor do córrego Pólvora, com cerca de $40 \mathrm{~m}$ de largura, que flui no sentido norte ao encontro do rio Piracicaba (Figura 4). Na porção nordeste do recorte (Figura 3), outra linha de transmissão passa por duas rodovias estaduais.

Entre os pontos em que a onça foi avistada, distantes entre si menos de dois quilômetros, há uma grande área de lazer junto ao rio Piracicaba, adjacente ao Parque da Rua do Porto.

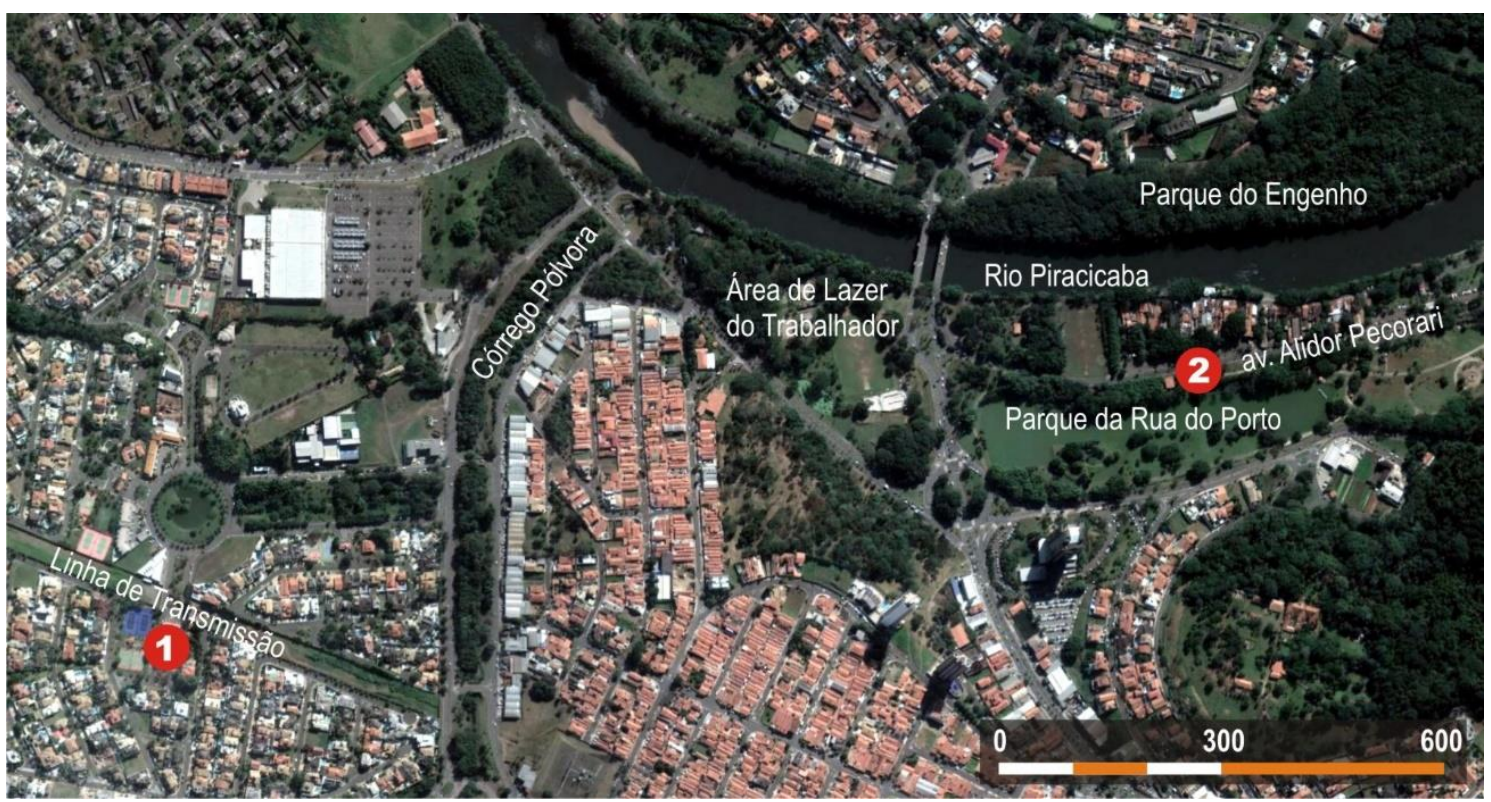

Figura 4. Região onde a onça foi avistada. Há grandes espaços livres, corredores fluviais, um corredor murado definido pela linha de transmissão de energia, parques, água. Cobertura vegetal varia, havendo pontos bem arborizados (fonte: imagem de satélite obtida do Google Earth em 01 fev. 2019, modificada pelo autor)

\section{Discussão}

Corredores são de fundamental importância como habitat ou como canal condutor de movimentos diários e dispersão para espécies que percorrem grandes distâncias. A paisagem estudada apresenta grandes espaços livres. Há áreas particulares, dentro e fora da cidade, como chácaras e sítios, reservas legais e plantações, com predominância de cana-de-açúcar e algumas áreas de silvicultura. Há também áreas públicas que têm experimentado significativa recuperação da cobertura vegetal. Múltiplos tipos de corredor percorrem a área, sejam eles naturais (cursos d'água e suas faixas ripárias) ou artificiais (vias arborizadas ou não, linhas de transmissão de energia elétrica, cercas vivas e parques).
Essa região do município vem

experimentando mudanças com relação ao uso do solo. Nos últimos 15 anos observou-se acréscimo significativo de edificações, surgimento e ocupação de novos condomínios horizontais, bem como mudanças no campo, redução e fragmentação de habitats com a expansão da infraestrutura urbana. A análise a seguir baseia-se em quatro perspetivas que podem ter influência nos movimentos da onça parda: a estrutura ou arranjos dos elementos da paisagem, os conflitos decorrentes dessa estrutura, as necessidades alimentares ou dieta da espécie abordada, e outros fatores.

\section{Estrutura da paisagem}

$\mathrm{O}$ rio Piracicaba percorre alguns poucos quilômetros dentro do perímetro urbano da 
cidade homônima (Figura 1). Tendo em vista que na literatura estão relatadas distâncias percorridas pela onça parda que compreendem vários quilômetros, é admissível que um indivíduo transponha toda a extensão dos corredores delineados na Figura 3 em uma única noite, sendo possível que procure abrigo fora da matriz urbana durante o dia, entre e saia da cidade, em busca de alimento, durante a noite, ou mesmo os percorra em busca de novos territórios. Cabe notar que, como descrito nos hábitos da espécie, a onça parda ocupa territórios extensos que podem superar a área do perímetro urbano.

De acordo com os dados referentes à sua história de vida, a onça parda pode utilizar ambientes com grande diversidade de cobertura vegetal, desde os mais naturais, variando de campos a florestas, aos mais humanizados, que incluem plantações de cana-de-açúcar e silvicultura. Como constatado, a espécie é capaz também de adentrar áreas urbanas que possuam espaços livres com estrutura e recursos adequados.

Forman (1995, p.241) afirma que "grandes mamíferos, como o leão da montanha ${ }^{2}[\ldots]$ são conhecidos por se moverem por muitos quilômetros ao longo de corredores de córregos e rios". Para Noss (1983 apud Giordano 2008, p.301), "corredores ao longo de rios podem funcionar como verdadeiras avenidas para organismos terrestres e aquáticos, principalmente se são grandes o suficiente para sustentar a existência de habitats para animais maiores".

Corredores fluviais, como dito anteriormente, favorecem os movimentos da onça parda. $\mathrm{O}$ rio Piracicaba é o maior corredor da área estudada. Corta-a acompanhado de vegetação ciliar em algumas porções, ladeado por vias ou parques em outras (Figura 2). Um de seus tributários, o córrego Pólvora, configura um corredor que conecta o rio Piracicaba com uma linha de transmissão de energia, a qual se estende para além dos limites urbanos, avançando para a zona rural, atravessando remanescentes florestais e plantações. Apesar da proximidade e uma certa contiguidade entre esses três elementos, eles são cortados por vias de grande movimento. A região do primeiro registro sofreu forte adensamento populacional nos últimos 15 anos (Figura 5), sendo essa porção do município marcada pelo desenvolvimento de condomínios de casas. A presença desses condomínios murados nas franjas do tecido urbano pode ter contribuído para criar um corredor seguro para a onça ao longo do traçado definido pela linha de transmissão.

Os corredores presentes na área são estreitos demais para serem considerados habitats para a onça parda, com exceção nas porções em que tocam grandes fragmentos remanescentes de mata nativa, normalmente em áreas fora do perímetro urbano. Para Forman (1995, p.149), "espécies raras e ameaçadas são normalmente ausentes, a menos que corredores representem essencialmente os únicos remanescentes de vegetação nativa na área". Entretanto, podem abrigar outros animais. Os meandros do rio Piracicaba e de seus tributários mantêm-se sinuosos e com significativa cobertura vegetal às suas margens, o que proporciona um grande contato com as matrizes urbanas e rurais que os circundam. Tais condições podem ser favoráveis para atrair outros animais que ali procuram por alimentos, água, abrigo ou rotas de dispersão e, assim, tornarem-se presas com potencial para atrair o felino. Além disso, a recomposição de vegetação ao longo de córregos, de espaços livres e de trampolins ecológicos pode ter facilitado os movimentos da onça.

Em 2003, um projeto de adequação ambiental e paisagística do trecho urbano do rio Piracicaba (Rodrigues e Lima, 2003) propôs medidas de recuperação da cobertura vegetal ao longo de córregos e em algumas áreas verdes próximas ao curso d'água. Como demonstram as imagens aéreas da Figura 5, entre os anos de 2003 e 2019 podese perceber um significativo aumento da cobertura vegetal em algumas áreas da cidade, como, por exemplo, ao longo do córrego Pólvora, mas não foi possível confirmar se há uma relação entre o projeto mencionado e as condições percebidas, ou ainda, se o significativo aumento da vegetação pode ter permitido e abrigado os deslocamentos da onça parda. Como o córrego Pólvora é adjacente a uma área de proteção de uma linha de transmissão de energia elétrica (Figura 4), cercada por muros de condomínios e com certa proximidade da zona rural, pode também ter desempenhado o papel de corredor para os deslocamentos da onça. Tais hipóteses são viáveis, uma vez que corredores ripários restaurados podem criar uma estrutura para dispersão (Cook, 1991). 

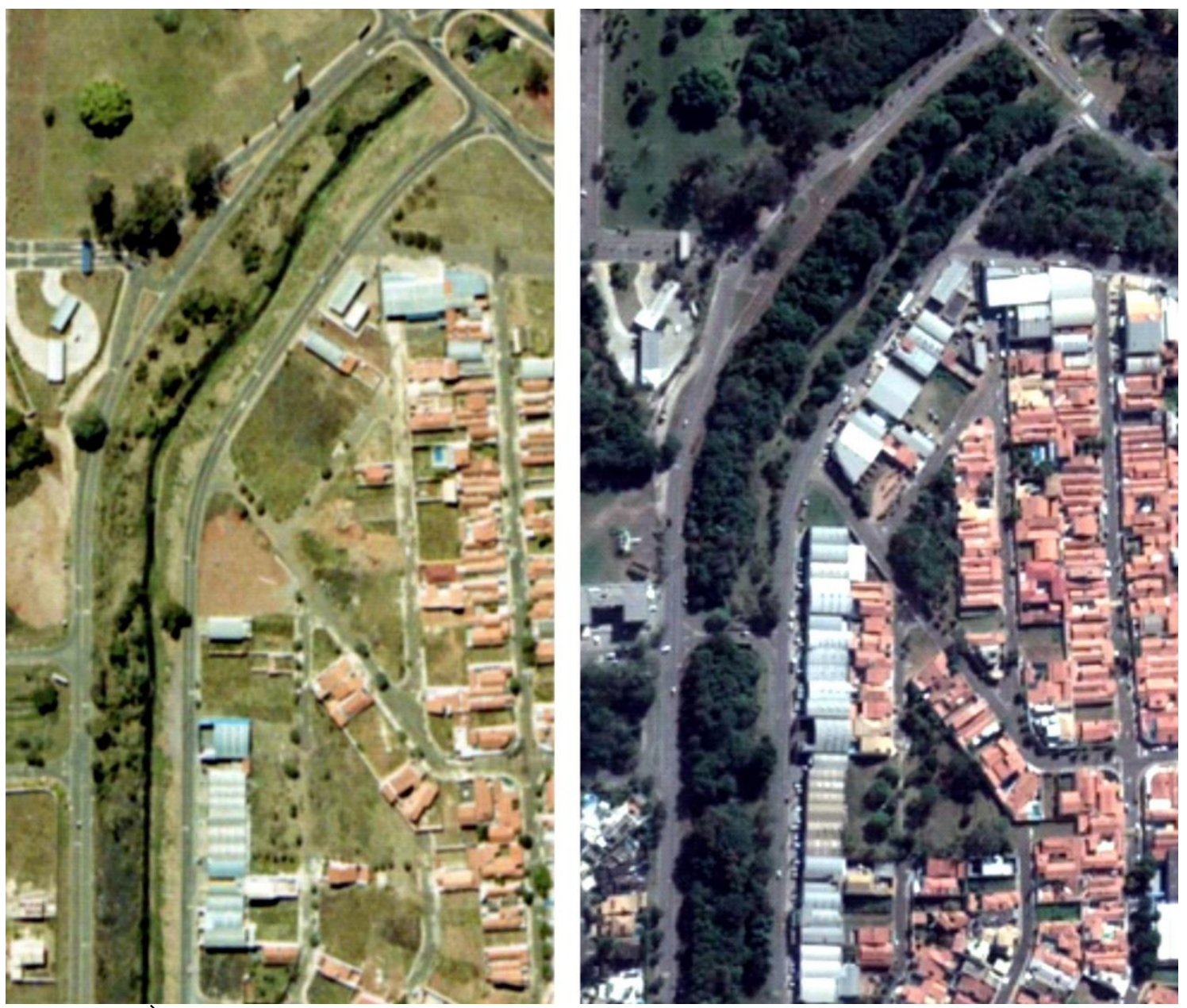

Figura 5. À esquerda, imagem aérea mostra faixa ribeirinha do córrego Enxofre com pouca cobertura vegetal (Fonte: Rodrigues e Lima, 2003); à direita, imagem recente mostrando a evolução da mata ciliar ao longo do mesmo córrego e a evolução da vegetação em áreas adjacentes (fonte: Google Earth, acesso em: 01 jul. 2019).

Conectividade é um fator importante para os movimentos de muitas espécies da fauna. A constatação do felino em áreas urbanas denota certa conectividade funcional e parcialmente estrutural. Conectividade funcional é o grau pelo qual uma paisagem facilita ou impede movimento entre territórios; conectividade estrutural é o grau pelo qual elementos de interesse de uma paisagem são contíguos ou fisicamente ligados entre si (Bélisle, 2005). Mesmo contíguos, os corredores da paisagem observada são frequentemente entrecortados por vias que podem representar potenciais conflitos.

\section{Conflitos}

Segundo Forman (1995, p.167), "atropelamentos podem ter um impacto significativo em populações de grandes mamíferos ou espécies raras". De fato, atropelamentos são considerados uma importante ameaça para a onça parda no
Brasil (Azevedo et al, 2013). Cruzamentos entre possíveis corredores com o sistema viário ocorrem ao longo dos percursos traçados. A nordeste da área estudada, por exemplo, onde matas ciliares conectam-se com linhas de transmissão de energia, esses corredores são cortados por rodovias estaduais (asteriscos na Figura 3). Nas imediações da área onde primeiro foi avistada a onça, avenidas de grande movimento, que dão acesso a condomínios, a um grande supermercado e a bairros e distritos rurais, margeiam tanto o córrego Pólvora quanto o rio Piracicaba (Figura 4). $\mathrm{Na}$ segunda vez que um espécime do felino foi avistado, percorria a avenida Alidor Pecorari, que apresenta risco de atropelamento.

\section{Dieta}

Naquela região, a presença de grandes mamíferos nativos geralmente restringe-se a capivaras (Hydrochoerus hydrochaeris), que 
fazem parte da dieta da onça parda e que são comumente vistas nas margens do rio Piracicaba e de outros cursos d'água. Tem-se observado o crescimento de populações de capivaras com o desenvolvimento da agricultura (Dotta e Verdade, 2011). Onças também se alimentam de gado. A região, entretanto, é dominada pelo plantio de canade-açúcar, havendo poucas oportunidades de alimentação como ocorre em regiões de produção pecuária. A fragmentação e redução de habitats pode ter levado à redução de oferta de alimentos nas áreas naturais e rurais, levando o felino a buscar alimentos dentro da cidade ou utilizar seus espaços livres - configurados como corredores - para dispersar para outras áreas.

\section{Outros fatores}

O plantio de cana-de-açúcar utiliza-se da queima no período da safra para facilitar sua colheita manual. Queimadas são ameaças à onça parda (Azevedo et al, 2013) e podem ter expulsado ou repelido indivíduos da zona rural, forçando-os a dispersar através de áreas urbanas em busca de novos e seguros territórios.

Em resumo, perceberam-se os seguintes espaços com características de corredor para a onça parda:

- Linhas de transmissão de energia elétrica, configuradas como áreas protegidas, relativamente isoladas das atividades urbanas e mantidas com vegetação rasteira;

- Córregos revegetados, conectando outros corredores, como as linhas de transmissão e as margens do rio Piracicaba;

- O parque da Rua do Porto, cortado pela avenida Alidor Pecorari, amplamente arborizada, paralela à margem esquerda do rio Piracicaba;

- As margens do rio Piracicaba, com cobertura vegetal variável, que recebe e conecta diversos tributários, criando uma rede de corredores dentro do tecido urbano e criando ligações com fragmentos florestais fora do perímetro urbano; e

- Rodovias, que podem servir, eventualmente, como recurso para dispersão.

Esses espaços possivelmente tornaram-se corredores ecológicos para a onça parda, permeando a cidade e conectando a matriz urbana com áreas rurais, onde remanescentes de mata e plantações propiciam refúgios diurnos. Especula-se também que elementos centrífugos - habitats reduzidos, atividades agrícolas, queima da cana para a colheita, novos loteamentos expandindo o perímetro urbano - atuando em conjunto com elementos atrativos - estrutura das comunidades vegetais, proteção e disponibilidade de alimentos (capivaras, aves, animais domésticos) próximo aos corpos d'água - contribuíram para suas incursões na cidade. A presença da onça parda e a constatação de que existe um sistema de espaços livre e especialmente corredores que atendem às necessidades dessa espécie, indicam que existe uma cadeia que inclui outros animais e, portanto, pode-se considerar que existam condições para sustentar biodiversidade.

A presença de um felino de grandes proporções em uma área urbana resulta, portanto, de motivações decorrentes de condições que o expulsaram de seu habitat, bem como de elementos atrativos e padrões paisagísticos que propiciaram seus deslocamentos, neste caso por um sistema de espaços livres que inclui corredores arborizados nas zonas ripárias, corredores protegidos sob as linhas de transmissão de eletricidade, fragmentos de mata e cerrados próximos às franjas urbanas e áreas agrícolas. Mesmo com obstáculos - vias, muros, descontinuidade dos corredores, conectividade incompleta, o felino foi capaz de percorrer espaços da cidade, não somente espaços livres protegidos com as linhas de transmissão, mas áreas densamente habitadas.

\section{Conclusão}

Este estudo é uma tentativa de compreender as relações entre os arranjos dos espaços livres de uma paisagem urbana e a biodiversidade, com foco em um evento atípico - a presença de um felino de grande porte no tecido urbano de uma cidade de médio porte.

A ocupação histórica às margens do rio Piracicaba por habitações e indústrias depauperou sua cobertura vegetal, reduziu ou transformou seu valor ecológico e contribuiu para a fragmentação do corredor fluvial original. Entretanto, nas últimas décadas, percebe-se um aumento da preocupação com suas margens. Vários projetos na orla fluvial, nas áreas de várzea e no entorno vêm sendo implementados, com ênfase nas áreas de 
lazer e de recuperação do recobrimento vegetal no trecho urbano do rio, além de outros projetos paisagísticos que prescrevem revegetação de tributários e espaços livres próximos ao corredor. O conjunto de projetos e intervenções de requalificação das áreas livres da cidade, apesar de não intencionalmente, acaba por conformar um corredor ecológico, mesmo que fragmentado, nos moldes de um parque linear (greenway), conectado com corredores de menor porte (tributários) e artificiais (linhas de transmissão), configurando uma rede de corredores que se estende para além do perímetro urbano. Esses corredores protegem recursos hídricos e conectam áreas urbanas; são de fundamental importância para processos ecológicos da paisagem, como o fluxo e disseminação de espécies, sejam de fauna ou da própria flora nativa. $\mathrm{O}$ arranjo dos espaços livres é, em vários casos, mais importante que a quantidade de habitats (Penteado 2014), tendo em vista que a viabilidade de certas espécies depende da sua capacidade de dispersar na paisagem, como acontece com o felino.

Além disso, corredores proporcionam benefícios para a população urbana na forma de espaços de lazer ou mesmo criando percursos alternativos entre diferentes áreas da cidade, favorecendo modos não motorizados de deslocamento, unindo questões socioculturais, econômicas e ambientais.

Apesar dos benefícios dos corredores para a sociedade e para a viabilidade da onça parda ao lhe proporcionar vias para sua dispersão na paisagem, sua existência revela um conflito ainda não resolvido: a configuração não intencional dos corredores ecológicos identificados na área urbana de Piracicaba teve como consequência inesperada a adoção das estruturas implantadas, pela onça, para sua dispersão, ocasionando a presença de um animal indesejado em áreas urbanas e aumentando a possibilidade de contato entre o animal e pessoas, podendo ocasionar prejuízos para ambos. A versatilidade da onça em adotar um amplo espectro de estruturas e coberturas vegetais poderia fazer com que o animal alcançasse áreas ainda mais indesejáveis, adentrando o tecido urbano.

A presença de outros exemplares da fauna silvestre ao longo dessa rede de corredores tem revelado, ainda, mais potenciais problemas. Por exemplo, capivaras hospedam e disseminam carrapatos estrela, que por sua vez podem carregar os vetores da febre maculosa. Inúmeras placas informativas ao longo das margens do rio alertam para sua possível ocorrência.

Apesar da importância dos corredores ecológicos dentro do tecido urbano para sustentação de biodiversidade e de atividades humanas, ainda não está claro como se poderia as conciliar e resolver os conflitos ocasionados pela presença de um predador de maior porte na cidade. O parque linear é importante para a manutenção de biodiversidade nas cidades, mas pode causar problemas inesperados como os relatados acima. Podem-se apontar, como alternativa, projetos que proponham a implantação de corredores fora do perímetro urbano maia atrativos e que conectem unidades de conservação, bem como a preservação de habitats nas áreas rurais que atendam às necessidades de espécies como a aqui abordada. Algumas iniciativas, como o Projeto Corredores Ecológicos do estado do Espírito Santo têm identificado áreas prioritárias de conservação e elaborado planos de ação para a implantação de grandes corredores (Instituto Estadual de Meio Ambiente e Recursos Hídricos, 2006).

O caso apresentado revela ainda um aprendizado importante. Os sistemas de espaços livres não podem ser pensados somente como manchas verdes desenhadas em mapas, comumente chamadas de áreas verdes. É necessário entender o contexto ecológico em que qualquer projeto paisagístico, em qualquer escala, está inserido e quais seres vivos, incluindo humanos, fauna e vegetação, vão ser afetados e como, e quais as possíveis consequências do projeto ou plano.

Teorias e métodos da ecologia da paisagem enquanto disciplina que estuda as relações entre a estrutura da paisagem e os processos ecológicos - podem contribuir para uma abordagem abrangente que colabore para a compreensão dos processos ecológicos em escala regional. Assim, a arquitetura e o urbanismo podem responder às questões envolvidas nas relações entre a sociedade e os ecossistemas no desenvolvimento de projetos e planos urbanos e regionais que conservem recursos ambientais, compreendam as necessidades das pessoas e do meio ambiente e assim, aperfeiçoem as 
maneiras pelas quais construímos ambientes que suportem todas as formas de vida.

\section{Notas}

${ }^{1}$ Este artigo foi submetido originalmente até o prazo de 20 de julho de 2019 ao PNUM 2019 Maringá. A seleção dos artigos foi feita pelos editores desta seção temática entre 24 de agosto e

\section{Referências}

Ahern, J. (2002). Greenways as strategic landscape planning: theory and application. $\mathrm{PhD}$ Dissertation, Wageningen University, Wageningen.

Alberti, M. (2005). The effects of urban patterns on ecosystem function. International Regional Science Review, 28(2), 168-192.

Arendt, R., Brabec, E. A., Dodson, H. L., Reid, C., e Yaro, R. D. (1994). Rural by design: maintaining small town character. Chicago, Ill.: Planners Press, American Planning Association.

Azanha, C. (2019). Onça parda é vista próximo ao parque da rua do Porto. Jornal de Piracicaba, 7 de janeiro de 2019.

Azevedo, F. C., Lemos, F. G., Almeida, L. B., Campos, c. B., Beisiegel, B. M., Paula, R. C., Crawshaw Junior, p. G., Ferazz, K. M. P. M. B. e Oliveira, T. G. (2018). Puma concolor (Linnaeus, 1771), in ICMBio/MMA, Livro Vermelho da Fauna Brasileira Ameaçada de Extinção: Volume II - Mamíferos / -- 1. ed. -- Brasília, DF: ICMBio/MMA

Azevedo, F. C., Lemos, F. G., Almeida, L. B., Campos, C. B., Beisiegel, B. M., Paula, R. C., Junior, P. G. C., Ferraz, K. M. P. M. B. e Oliveira, T. G. (2013). Avaliação do risco de extinção da onça-parda Puma concolor (Linnaeus, 1771) no Brasil. Biodiversidade Brasileira. 0 (1), 107-121.

Baschak, L. e Brown, R. D. (1995). An ecological framework for planning and management of urban river greenways. Landscape and Urban Planning $33,211-225$.

Beardsley, K., Thorne, J. H., Roth, N. E., Gao, S. e McCoy, M. C. (2009). Assessing the influence of rapid urban growth and regional policies on biological resources. Landscape and Urban Planning, 93(3-4), 172-183.

Bélisle, M. (2005). Measuring Landscape Connectivity: The Challenge of Behavioral Landscape Ecology. Ecology, Vol. 86, No. 8 (Aug., 2005), 1988-1995

Bryant, M. M. (2006). Urban landscape conservation and the role of ecological greenways at local and metropolitan scales. Landscape and Urban Planning, 76(1-4), 23- 44.
29 de outubro de 2019. As versões revisadas foram enviadas até o dia 10 de dezembro de 2019.

${ }^{2}$ Leão da montanha (mountain lion) é uma das denominações populares do Puma concolor na América do Norte.

Cook, E. A. (1991). Urban landscape networks: an ecological framework. Landscape Research, 16,715.

Dotta, G. e Verdade, L. M. (2011). Medium to large-sized mammals in agricultural landscapes of south-eastern Brazil. Mammalia, 75 (4), 345-352.

Ferrari, S. F. (2009). Predation Risk and Antipredator Strategies, in Garber, P.A.; Estrada, A.; Bicca-Marques, J.C.; Heymann, E.W.; Strier, K.B. South American Primates: Comparative Perspectives in the Study of Behavior, Ecology, and Conservation. Nova Iorque: Springer, pp. 251-279. ISBN 978-0-387-78705-3

Forman, R. T. T. (1995). Land mosaics: the ecology of landscapes and regions. Cambridge [England]; New York: Cambridge University Press.

Forman, R. T. T. (2008). Urban regions: ecology and planning beyond the city. Cambridge, UK: Cambridge University Press.

Forman, R. T. T. e Godron, M. (1986). Landscape Ecology. New York: John Wiley and Sons

Giordano, L. C., Riedel, P.S. (2008). Multi-criteria spatial decision analysis for demarcation of greenway: A case study of the city of Rio Claro, São Paulo, Brazil. Landscape and Urban Planning 84 (2008) 301-311

Hobbs, R. (1997). Future landscapes and the future of landscape ecology. Landscape and Urban Planning 37, 1-9.

Hough, M. (2004). Cities and natural process: a basis for sustainability (2nd ed.). Nova Iorque: Routledge.

Instituto Estadual de Meio Ambiente e Recursos Hídricos. (2006). Projeto Corredores Ecológicos: Síntese do processo de definição e planejamento dos corredores prioritários no Espírito Santo. Cariacica

Ipplap (2017). Mapa abairramento e loteamentos 2017 F. Disponível em http://ipplap.com.br/ site/mapas/

Iriarte, J. A., Franklin, W. L., Johnson, W. E.1. (1990). Biogeographic variation of food habits and body size of the America puma. Oecologia (1990) 85: 185. 
Logan, K. A. e Sweanor, L.L. (2010). Behavior and Social Organization of a Solitary Carnivore, in: Hornocker, M. G., \& Negri, S. Cougar: ecology and conservation. Chicago, Illinois, USA: University of Chicago Press, 105-118.

Moss, M. R. 2000. "Landscape ecology: the need for a discipline?" In Richling, A. et al (editors), Landscape ecology - theory and applications for practical purposes. Warsaw: Pultusk School of Humanities, IALE, and Polish Association for Landscape Ecology, 172-185.

Ndubisi, F., DeMeo, T., e Ditto, N. D. (1995). Environmentally sensitive areas: a template for developing greenway corridors. Landscape and Urban Planning, 33(1-3), 159-177.

Novack, A. J., Main, M. B., Sunquist, M. E. e Labisky, R. F. (2005), Foraging ecology of jaguar (Panthera onca) and puma (Puma concolor) in hunted and non-hunted sites within the Maya Biosphere Reserve, Guatemala. Journal of Zoology, 267, 167-178. doi: 10.1017/ S0952836905007338

Opdam, P., Steingrover, E., e Rooij, S. v. (2006). Ecological networks: A spatial concept for multiactor planning of sustainable landscapes. Landscape and Urban Planning, 75, 322-332.

Pellegrino, P. R. M., Guedes, P. P., Pirillo, F. C. e Fernandes, S. A. (2006). A paisagem da borda: uma estratégia para a condução das águas, da biodiversidade e das pessoas. In Costa, L. M. S. A. (org.), Rios e paisagens urbanas em cidades brasileiras. Rio de Janeiro: Viana e Mosley: Ed. PROURB.

Penteado, H. (2013). Assessing the effects of applying landscape ecological spatial concepts on future habitat quantity and quality in an urbanizing landscape. Landscape Ecology, 28(10), 19091921.

Penteado, H. (2014). Open Space as an Armature for Urban Expansion: A Future Scenarios Study to Assess the Effects of Spatial Concepts on Wildlife Populations. PhD Dissertation, University of Oregon, Eugene.

Penteado, H. M., e Alvarez, C. E. (2007). Corredores verdes urbanos: estudo da viabilidade de conexão das áreas verdes de Vitória. Paisagem e Ambiente, 24, 57-68.

Penteado, M.J.F. (2012). Áreas de vida, padrões de deslocamento e seleção de habitats por pumas (Puma concolor) e jaguatiricas (Leopardos pardalis), em paisagens fragmentadas de São Paulo. 139f. Tese de Doutorado. Instituto de Biologia, Universidade Estadual de Campinas, Campinas.

Rocha, M. Onça é flagrada por câmeras de condomínio. Gazeta de Piracicaba, 4/4/2017

Rodrigues, R. R. e Lima, A. M. L. P. (2003). Proposta de Adequação Ambiental e Paisagística do Trecho Urbano do Rio Piracicaba e Entorno. Disponível em http://www.ipplap.com.br/ docs/PAAP-PARTE\%201-8.pdf

Schumaker, N. H. (1996). Using Landscape Indices to Predict Habitat Connectivity. Ecology, 77(4), 1210-1225.

Scognamillo, D, Maxit, I. E., Sunquist, M. e Polisar, J. (2003), Coexistence of jaguar (Panthera onca) and puma (Puma concolor) in a mosaic landscape in the Venezuelan llanos. Journal of Zoology, 259, 269-279. 


\section{Tradução do título, resumo e palavras-chave}

The puma in the gated community: the role of urban ecological corridors

Abstract. Open spaces may provide habitat for wildlife in urban areas, but larger species are rarely sighted. A puma (Puma concolor) was captured on video in Piracicaba, SP, which created an interest in investigating which landscape patterns (shapes, dimensions, spatial relationships between urban matrix, corridors and habitat fragments, vegetation, etc.) enabled movements from rural areas to a city of approximately 400 thousand inhabitants. Aerial images, photographs and interpretive maps were used. The puma was spotted at two areas near to each other, from which routes were traced to identify possible corridors and refuges. Possible ecological corridors include spaces under power lines surrounded by condominium walls, riparian forests along streams and the Piracicaba River, or even tree-lined avenues that permeate the city, connect the urban matrix with rural areas and provide access to sources of food (capybaras, domestic animals). The presence of the feline in the urban area can therefore result from conditions that drove it out of its habitats, attractive elements in the city and landscape patterns that enabled its movements.

Keywords. ecological corridor, open space, biodiversity, urban morphology, landscape ecology.

Editores responsáveis pela submissão: Karin Schwabe Meneguetti, Renato Leão Rego e Gislaine Elizete Beloto.

Licenciado sob uma licença Creative Commons.

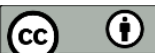

